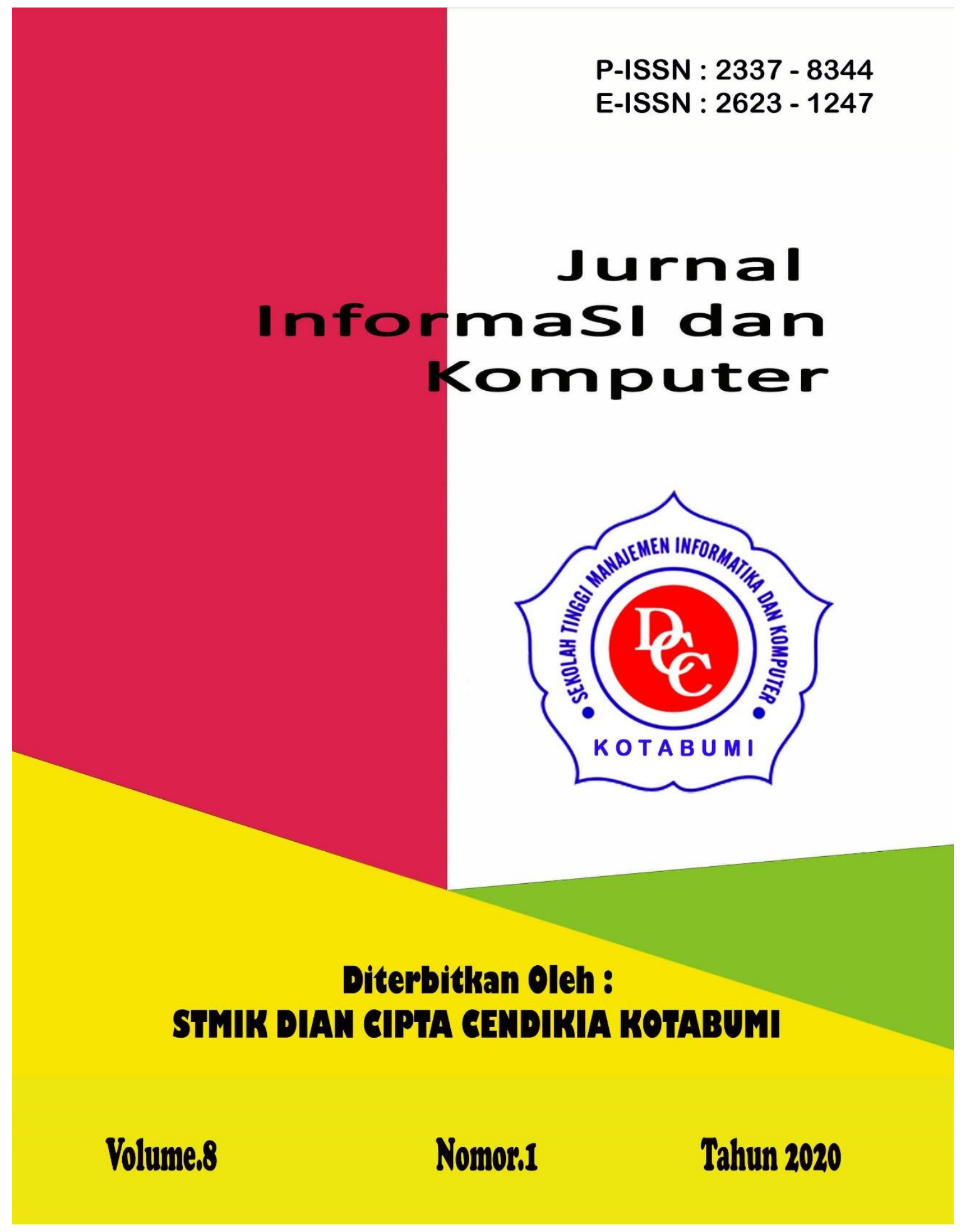




\section{Penerbit:}

STMIK DIAN CIPTA CENDIKIA KOTABUMI

Bekerjasama dengan LPPM STMIK DCC Kotabumi

Hak atas naskah/tulisan tetap berada pada penulis, isi diluar tanggung jawab

Penerbit dan Dewan Penyunting

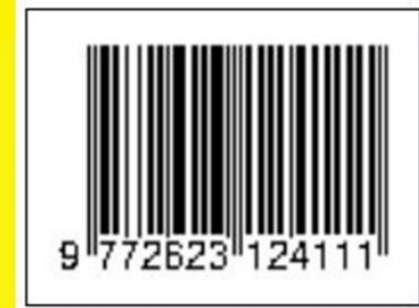




\section{PENGANTAR REDAKSI}

Puji syukur dipanjatkan kehadirat Tuhan Yang Maha Esa, atas karunia dan limpahan rahmatNYA jualah Jurnal Informatika dan komputer (InfoKom) STMIK Dian Cipta Cendikia Kotabumi ini dapat terwujud.Jurnal Informatika dan Komputer (InfoKom) yang terbit dua (2) kali dalam setahun ini merupakan suatu wadah untuk penyebar luasan hasil-hasil penelitian, studi pustaka, karya ilmiah yangberkaitan dengan Informatika dan Komputer khususnya bagi dosen-dosen STMIK Dian Cipta Cendikia Kotabumi serta umumnya para cendikiawan, praktisi, peneliti ilmu Informatika dan Komputer.

Harapan, dengan diterbitkannya Jurnal Informatika dan Komputer (InfoKom) ini sebagai salah satu bentuk sumbangan pemikiran dalam pengembangan ilmu informatika dan komputer yang berkaitan dengan kajian-kajian di bidang tekhnologi Informatik, Komunikasi Data dan Jaringan Komputer, perancangan dan Rekayasa Perangkat Lunak, serta ilmu-ilmu yang terkait dengan bidang Informatika dan Komputer lainnya.

Berkenaan dengan harapan tersebut, kepada para peneliti, dosen dan praktisi yang memiliki hasil-hasil penelitian, kajian pustaka, karya ilmiah dalam bidang tersebut diatas, dengan bangga redaksi Jurnal Informatika dan Komputer (JIK) menerima naskah ringkasan untuk dimuat pada jurnal Informatika dan Komputer (InfoKom) STMIK Dian Cipta Cendikia Kotabumi dengan berpedoman pada penulisan naskah jurnal sebagaimana dilampirkan pada halaman belakang (Bagian kulit dalam) buku jurnal ini.

Mutu dari suatu jurnal ilmiah tidak hanya ditentukan oleh para pengelolanya saja, tetapi para penulis dan pembaca jualah yang mempunyai peranan besar dalam meningkatkan mutu jurnal Informatika dan Komputer ini. Merujuk pada realita ini kamu sangat mengharapkan peran aktif dari peneliti untuk bersama-sama menjaga dan memelihara keberlangsungan dari jurnal Informatika dan Komputer STMIK Dian Cipta Cendikia Kotabumi ini. Yang juga tidak kalah pentingnya dari partisipasi tersebut diatas, adalah saran dan kritik yang membangun dari pembaca yang budiman agar kiranya dapat disampaikan langsung kepada redaksi JIK. Saran dan kritik yang membangun akan dijadikan masukan dan pertimbangan yang sangat berarti guna peningkatan mutu dan kualitas Jurnal Informatika dan Komputer STMIK Dian Cipta Cendikia Kotabumi.

Tak lupa diucapkan terima kasih yang tak terhingga atas perhatian dan kerjasama dari semua pihak yang tak dapat disebutkan satu persatu hingga dapat diterbitkan nya Jurnal Informatika dan Komputer (InfoKom) STMIK Dian Cipta Cendikia Kotabumi. Semoga apa yang telah diperbuat untuk kebaikan akan menjadi amal ibadah, amin.

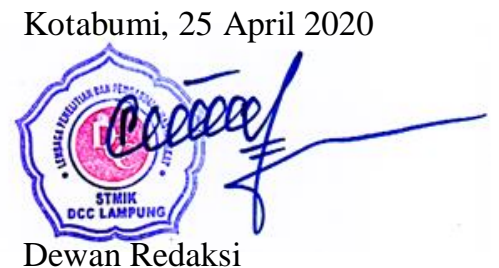




\section{JURNAL INFORMASI DAN KOMPUTER}

Volume 8 Nomor 1 April 2020

Jurnal Informasi dan Komputer merupakan Sarana informasi ilmu pengetahuan, Tekhnologi dan Komunikasi yang berupa hasil penelitian, tulisan ilmiah, Ataupun studi pustaka. Jurnal ini terbit dua kali setahun pada bulan April dan Oktober. Berisi hasil penelitian ilmiah di bidang informatika yang bertujuan untuk menghubungkan adanya kesenjangan antar kemajuan teknologi dan hasil penelitian. Jurnal ini di terbitkan pertama kali pada tahun 2013.

Penanggung Jawab:

Ketua STMIK Dian Cipta Cendikia

Kotabumi

\section{Pembina:}

Ketua STMIK Dian Cipta Cendikia

Kotabumi

Ketua Lembaga Penelitian STMIK Dian

Cipta Cendikia Kotabumi

\section{Pimpinan Redaksi}

Dwi Marisa Efendi,.S.Kom.,M.Ti

\section{Redaksi pelaksana}

Rustam,.S.Kom,.M.Ti (STMIK Dian

Cipta Cendikia Kotabumi)

Nurmayanti M.Kom (STMIK Dian

Cipta Cendikia Kotabumi)

Sukatmi,.S.Kom., M.Kom (AMIK DCC

Bandar Lampung)

Sampurna Dadi Riskiono,M.Kom

(Universitas Teknokrat Indonesia)

Ifo Wahyu

Pratama,S.Kom.,M.Ti(AMIK MASTER

Lampung)

\section{Mitra Bestari}

Merri Parida.,M.Kom (STMIK Dian

Cipta Cendikia Kotabumi)

Amarudin,S.Kom.,M.Eng (Universitas

Teknokrat Indonesia)

Didi Susianto.,S.T.,M.Kom (AMIK

DCC Bandar Lampung)

Alhibarsyah.,S.T.,M.Kom (Stmik Tunas

Bangsa Bandar Lampung)

Kemal Farouq Mauladi

.,S.Kom.,M.Kom (Universitas Islam

Lamongan)

Agus Setiawan S.Pd.,M.Eng

(Universitas Muhammadiyah

Lamongan)

Penerbit : STMIK Dian Cipta Cendikia Kotabumi Bekerja Sama Dengan LPPM STMIK Dian Cipta Cendikia Kotabumi.

\section{Alamat Redaksi/Penerbit:}

Jl. Negara No. 3 Candimas Kotabumi

Lampung Utara

No Telpon/Fax 072423003

Email : 1ppm-stmik@dcc.ac.id 


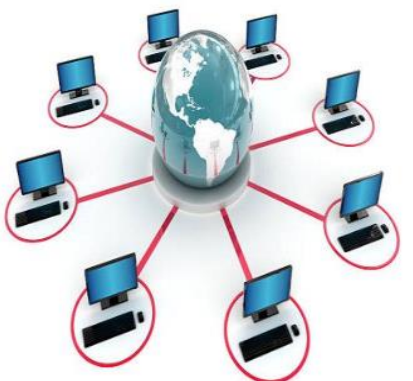 \\ JURNAL INFORMASI DAN KOMPUTER VOL. 8 NO. 1 THN. 2020}

\section{DAFTAR ISI}

\section{Halaman}

Sistem Pendukung Keputusan Penentuan Lahan Kopi Terbaik Dengan Metode

Ahp (Analytic Hierarchy Process)

Sidik Rahmatullah, Rendy Abdurahman (AMIKKOM Jogja,

STMIK Dian Cipta Cendikia Kotabumi)

Rancang Bangun Sistem Informasi Pada Program Pembangunan Pemberdayaan

Masyarakat Desa( P3md ) Berbasis Web Mobile

Ferly Ardhy, Firmansyah, Sidik Rahmatullah,(IIB Darma Jaya Bandar Lampung

STMIK Dian Cipta Cendikia Kotabumi, AMIKKOM Jogja)

Sistem Informasi Pengolahan Data Alumni Sekolah Menengah Atas (Sma)

Merri Parida, Nindiya Ova Rahmawati (AMIKKOM Jogja,

STMIK Dian Cipta Cendikia Kotabumi)

SISTEM INFORMASI GEOGRAFIS PUSKESMAS BESERTA SARANA

DAN PRASARANA BERBASIS WEB MOBILE

Nurmayanti, Windy Dwi Bahari (AMIKOM Jogja,

STMIK Dian Cipta Cendikia Kotabumi)

Rancang Bangun Sistem Informasi Konseling Untuk Sekolah Menengah Kejuruan

(Smk) Berbasis Website

Aliy Hafiz1, Galih Rakasiwi, Ifo Wahyu Pratama, Agus Komarudin,

Bambang Suparapto, Fathurrahman Kurniawan Ikhsan

(AMIK Dian Cipta Cendikia Bandar Lampung,

Universitas Nahdhatul Ulama Lampung, AMIK Dian Cipta Cendikia Pringsewu,

Universitas Mitra Indonesia, Lampung) .....

Sistem Pendukung Keputusan Pemilihan Driver Terbaik Menggunakan Metode

Weight Product (Wp)

Dina Lorenza, Pitrawati (STMIK Dian Cipta Cendikia Kotabumi

AMIK Dian Cipta Cendikia)

Rancang Bangun Sistem Informasi Pembayaran Mahasiswa

Darsin(Universitas Megou pak Tulang Bawang)

Sistem Informasi Geografis Bengkel Motor Honda Resmi Bandar Lampung

Sukatmi, Nuraini (AMIK Dian Cipta Cendikia Bandar Lampung).....

Sistem Pakar Diagnosa Penyakit Kulit Wajah Dengan Metode

Certainty Factor Pada Klinik Skin Rachel

Dwi Marisa Efendi, Putri Yulita Sari (IIB Darmajaya Bandar Lampung,

STMIK Dian Cipta Cendikia Kotabumi) 
Sistem Informasi Monitoring Siswa Pada Mts Al-Islamiah Bunut Kabupaten Pesawaran Yuli Syafitri ${ }^{2}$, Reni Astika ${ }^{1}$, Septian Hernando $^{3}$ AMIK Dian Cipta Cendikia

Aplikasi Kamus Bahasa Jepang Berbasis Mobile Android

Rustam $^{2}$, A Yanda Febry Pangestu ${ }^{2}$ Sistem Informasi, Teknologi Komputer ${ }^{1}$, IIB Darmajaya

Bandar Lampung ${ }^{2}$ STMIK Dian Cipta Cendikia Kotabumi 


\title{
SISTEM INFORMASI MONITORING SISWA PADA MTS AL-ISLAMIAH BUNUT KABUPATEN PESAWARAN
}

\author{
Yuli Syafitri $^{2}$, Reni Astika ${ }^{1}$, Septian Hernando ${ }^{3}$ \\ AMIK Dian Cipta Cendikia \\ Jl. Cut Nyak Dien No.65 Durian Payung (Palapa) Bandar Lampung \\ nandonaol19@gmail.com ${ }^{1}$, ayulisyafitri@gamil.com ${ }^{2}$
}

\begin{abstract}
ABSTRAK
Selama ini pengawasan terhadap siswa sebagian besar hanya dilakukan oleh pihak sekolah. Dengan tingkat kesibukan yang tinggi, orang tua minim melakukan memonitoring terhadap perkembangan anakanaknya di sekolah. Informasi tentang perkembangan proses belajar siswa biasanya hanya diterima orang tua sekali dalam satu semester, yakni saat terima raport. Jika siswa melakukan pelanggaran, maka pihak sekolah akan memanggil orang tua dengan cara mengirimkan surat panggilan. Biasanya pelangaran yang dilakukan meliputi absensi, nilai, keterlambatan pembayaran uang sekolah (uang OSIS), dan kasus-kasus pelanggaran lain yang dilakukan siswa. Tujuan penelitian ini sistem informasi monitoring siswa agar dapat mengurangi siswa bermasalah yang ada di MTs Al-Islamiah Bunut Kabupaten Pesawaran seperti: Kehadiran siswa siswa,Kedisiplinan sswa, dan pemberitahuan informasi tentang sekolah sekolah. Metode pengembangan sistem pada penelitan ini adalah Xxtreme Programming (XP). Hasil dari penelitian ini berupa aplikasi pengolahan data dapat menghasilkan informasi yang dibutuhkan secara efektif dan efisien sehingga pembuatan laporan monitoring siswa pada MTs Al Islamiah Bunut Kabupaten Pesawaran tidak terlambat. Selain itu sistem yang baru ini lebih mudah dalam proses pengolahan data Monitoring Siswa .
\end{abstract}

Kata kunci : Monitoring, Pelanggaran, Web.

\begin{abstract}
S
All this time observation to student a large part just did by school party. With tall rushing zoom, minim oldster does monitoring to its children developing at school. Information about process developing studies student just usually accepted by oldster once deep one semester, namely while accepts raport. If student does breach, therefore school party will call oldster by sends writ. Usually pelangaran which doing to cover absence, point, moneys paying delay schooled (OSIS'S money), and other breach cases that done by student. It obviously doesn't give a lot of solution since oldster not give observation since early. To the effect this research student monitoring information system to be able to reduce troublesome student that is at MTs Al Islamiah Bunut Kabupaten Pesawaran as: Student presents,sswa's discipline, and informer about school. Systems developmental method on this final task is Xxtreme Programming $(X P)$. Result of this research as application of data processing can result needed information effectively and efficient so Monitoring reporting makings student on MTs Al Islamiah Bunut Pesawaran's Regency not late. Besides system this a new one a lot easier in Monitoring data processing process student.
\end{abstract}

Keywords: Monitoring, Breach, Web. 


\section{PENDAHULUAN}

Selama ini pengawasan terhadap siswa sebagian besar hanya dilakukan oleh pihak sekolah. Dengan tingkat kesibukan yang tinggi, orang tua minim melakukan memonitoring terhadap perkembangan anak-anaknya di sekolah. Informasi tentang perkembangan proses belajar siswa biasanya hanya diterima orang tua sekali dalam satu semester, yakni saat terima raport. Jika siswa melakukan pelanggaran, maka pihak sekolah akan memanggil orang tua dengan cara mengirimkan surat panggilan. Biasanya pelangaran yang dilakukan meliputi absensi, nilai, keterlambatan pembayaran uang sekolah (uang OSIS), dan kasus-kasus pelanggaran lain yang dilakukan siswa. Hal ini tentu tidak memberikan banyak solusi karena orang tua tidak memberikan pengawasan sejak awal. Kondisi pengawasan seperti ini terjadi di MTs Al-Islamiah Bunut yang berada di Kecamatan Way Ratay, Kabupaten Pesawaran.

Adapun tujuan penelitian ini adalah Membangun sistem informasi monitoring siswa agar dapat mengurangi siswa bermasalah yang ada di MTs Al-Islamiah Bunut Kabupaten pesawaran seperti:

1. Kehadiran siswa

2. Kedisiplinan siswa

3. Pemberitahuan informasi tentang sekolah.

Adapun manfaat penelitian ini adalah :

1. Dengan adanya sistem monitoring ini di harapkan agar orang tua dan sekolah dapat saling bekerja sama dalam membing siswa/siswi menjadi lebih baik lagi kedepannya.

2. Dengan adanya sistem monitoring ini diharapkan mengurangi pelanggaran yang dilakukan siswa disekolah.

\section{KAJIAN PUSTAKA}

\subsection{Sistem Informasi}

Menurut Yusuf Sutarman (2010) : "Sistem Informasi adalah kombinasi dari teknologi informasi dan aktifitas orang yang menggunakan teknologi itu untuk mendukung operasi dan manajemen. Dalam arti yang sangat luas, istilah sistem informasi yang sering digunakan merujuk kepada interaksi antar orang, proses algoritmik, data dan teknologi. Dalam pengertian ini, istilah ini digunakan untuk merujuk tidak hanya pada penggunaan organisasi Teknologi Informasi dan Komputer (TIK).’'[1]

\subsection{Monitoring}

Menurut Ahmad Salamun (2013) : "Sistem adalah suatu jaringan kerja dari prosedurprosedur yang saling berhubungan, berkumpul bersama-sama untuk melakukan suatu kegiatan atau untuk menyelesaikan suatu sasaran yang tertentu. Suatu sistem memiliki karakteristik atau sifat-sifat tertentu, yaitu : komponen sistem, batas sistem, lingkungan luar sistem, penghubung sistem, masukan sistem, keluaran sistem, pengolah sistem, dan sasaran sistem.’[2]

\subsection{WEB}

Menurut Edhy Sutanta (2010) : "Banyak orang yang beranggapan website semua dengan internet. Padahal, website dan internet adalah hal yang berbeda. Website atau di singkat web, dapat di artikan sekumpulan halaman yang terdiri atas beberapa laman yang berisi beberapa laman yang berisi informasi dalam bentuk digital, baik berupa teks, gambar, video, audio dan animasi."[3]

\subsection{Pengembangan}

Menurut Alim Sumarno (2012)

"Pengembangan adalah proses menterjemahkan atau menjabarkan spesifikasi rancangan kedalam bentuk fitur fisik. Pengembangan secara khusus berarti proses menghasilkan bahan-bahan pembelajaran pada analisis kebutuhan, tetapi juga isu-isu luas tentang analisis awal-akhir, seperti analisi kontekstual.’'[4]

\section{METODELOGI PENELITIAN}

\subsection{Metode Pengumpulan Data}

Dibawah ini ada metode pengumpulan data yang digunakan:

1. Wawancara (Interview)

Ditahap ini peneliti menyiapkan pertanyaan untuk wawancara secara langsung kepada pimpinan.

2. Pengamatan (Observasi)

Ditahap ini peneliti meninjau langsung ke MTs Al-Islamiyah Bunut Kabupaten Pesawaran dengan mendapatkan izin 
terlebih dahulu dari pimpinannya.

3. Studi Pustaka

Ditahap ini peneliti mencari informasi dari berbagai literature baik dari buku, perpustakaan, e-book, dan pembelian buku ditoko buku.

\subsection{Metode Pengembangan Sistem}

Metode pengembangan sistem yang digunakan adalah Xtreme Programming.

Menurut Widodo (2014) : "Xtreme Programming (XP) merupakan salah satu contoh metodologi pengembangan cepat atau bisa disebut AGILE dalam pengembangan sistem informasi."[5]

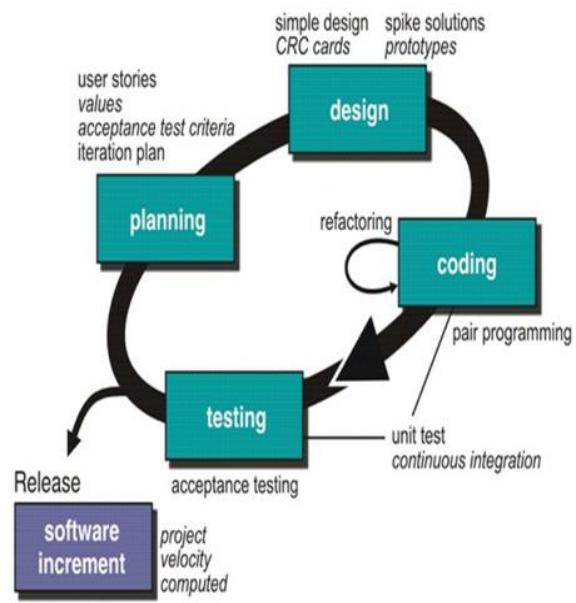

Gambar 1. Kerangka Kerja XP Sumber : Syafitri, Y. (2016), jurnal cendikia [6]

Adapun tahap-tahap dalam Metode Extreme Programming (XP) antara lain :

1. Planning

Proses yang mendefinisikan tujuan dari organisasi, membuat strategi digunakan untuk mencapai tujuan dari organisasi, serta mengembangkan rencana aktivitas kerja organisasi.

2. Desain

Perencanaan dalam pembuatan sebuah objek, sistem, komponen, atau struktur. Dalam hal ini dapat berupa proposal, gambar, model, maupun deskripsi.

3. Coding

Proses penulis, menguji, memperbaiki (debug), dan memelihara kode yang membangun sebuah program komputer.
Kode ditulis dalam berbagai Bahasa Pemrogramman.

4. Testing

Proses pemantapan kepercayaan akan kinerja program atau sistem sebagaimana yang diharapkan.

\section{HASIL DAN PEMBAHASAN}

Berdasarkan proses penelitian yang dilakukan oleh peneliti tentang pengembangan Sistem Informasi Monitoring Siswa pada MTs Al Islamiah Bunut Kabupaten Pesawaran, maka dihasilkan sebuah aplikasi yang dapat memberikan informasi monitoring siswa ke orang tua sehingga orang tua dapat mengetahui kegiatan siswa dalam hal ini kehadiran dan catatan pelanggaran siswa selama di sekolah. Aplikasi ini berextentantion exe dengan alamat http://www.monitoring_siswa3.com yang dapat diakses oleh orangtua, guru, dan pihak sekolah.

Adapaun fitur-fitur pada aplikasi ini adalah sebagai berikut :

Menu Utama terdiri dari sub menu master, transaksi, laporan dan log out. Tampilan menu utama dapat dilihat pada Gambar 4.1 berikut ini :

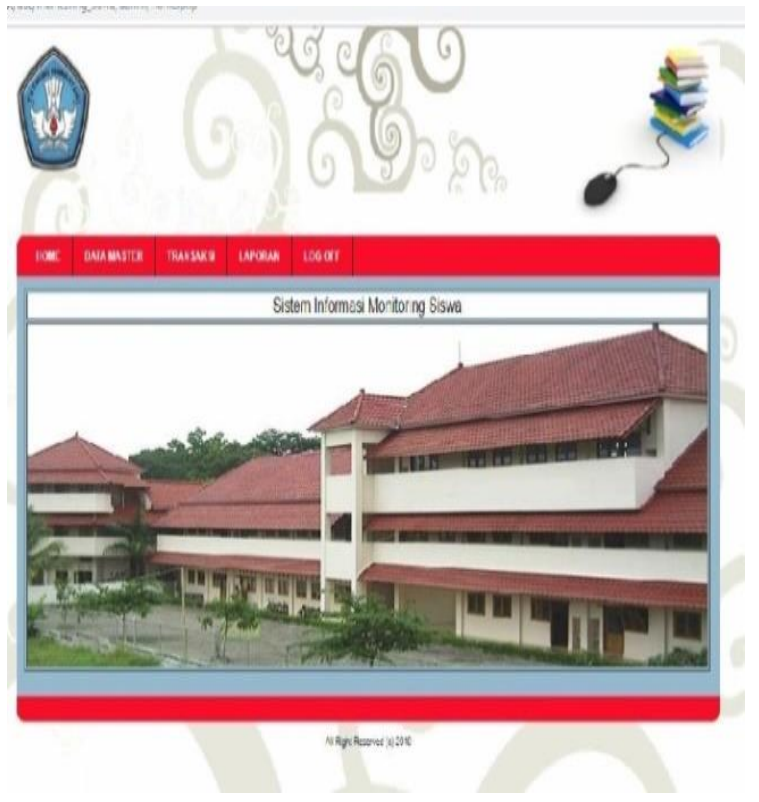

Gambar 4.1 Tampilan Menu Utama

Login digunakan sebelum memasuki tampilan program utama. Tampilan form login dapat dilihat pada Gambar 4.2 berikut ini 


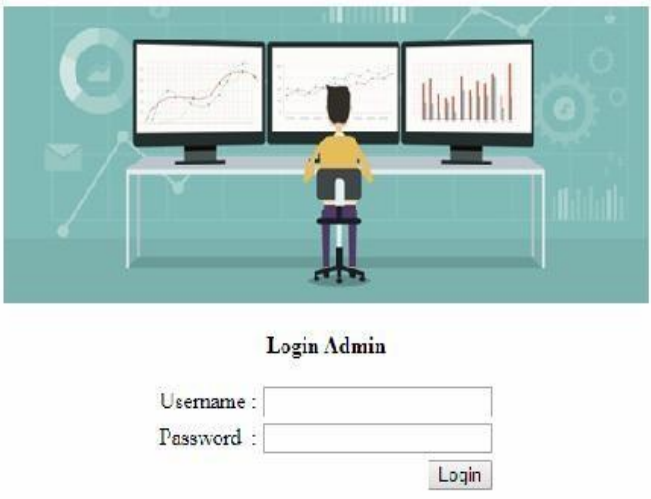

Gambar 4.2 Tampilan Login

Form input data Kelas berfungsi untuk mengolah data Kelas. Tampilan input data Kelas dapat dilihat pada Gambar 4.3 berikut ini :

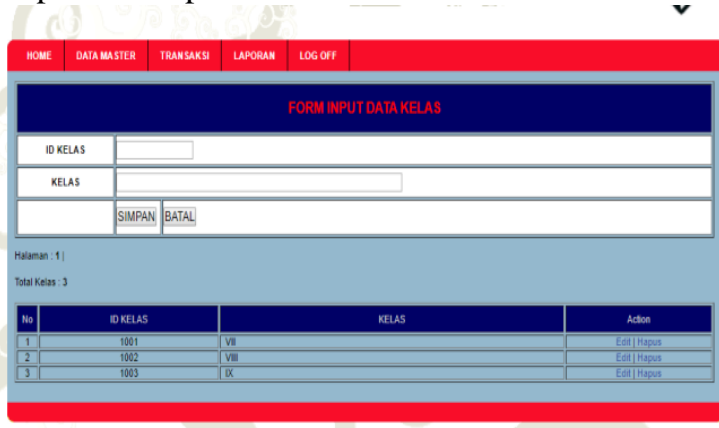

Gambar 4.3 Tampilan Input Data Kelas

Form ini berfungsi untuk mengolah data Siswa. Tampilan input Siswa dapat dilihat pada Gambar 4.4 berikut ini :

\begin{tabular}{|c|c|c|c|c|c|c|c|}
\hline \multicolumn{8}{|c|}{ FORM INPUT DATA SISWA } \\
\hline \multicolumn{8}{|l|}{ somor mouk sisma - } \\
\hline \multicolumn{8}{|l|}{ nama sissua } \\
\hline \multicolumn{8}{|l|}{ nемат } \\
\hline Agama & \multicolumn{7}{|c|}{ Stam $\quad \square$} \\
\hline JENIS KELAMN & \multicolumn{7}{|l|}{$\theta_{\text {pia } 0}$ ments } \\
\hline таним Алден & \multicolumn{7}{|l|}{$\square$} \\
\hline keus & \multicolumn{7}{|l|}{ Piinh Kelass } \\
\hline semesster & \multicolumn{7}{|l|}{$\quad$} \\
\hline & \multicolumn{7}{|l|}{ SIMPAN BATAL } \\
\hline \multicolumn{8}{|l|}{ 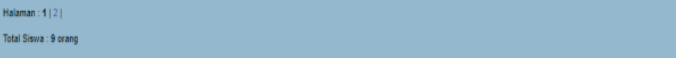 } \\
\hline 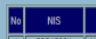 & Nom Sima & & Nent & hom & satel & \begin{tabular}{l|l|} 
Th & Kases \\
\end{tabular} & Adeson \\
\hline 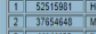 & Nantan & $\frac{b u}{b x}$ & & him & PARATA & 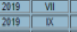 & 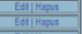 \\
\hline 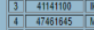 & 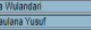 & bene & & titam & PQRATh & \begin{tabular}{|l|l|}
219 \\
219 \\
219
\end{tabular} & 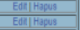 \\
\hline 5 & & bund & & & & \begin{tabular}{ll|l|}
2019 & vil \\
\end{tabular} & Easl Hepon \\
\hline
\end{tabular}

Gambar 4.4 Tampilan Input Data Siswa

Form ini berfungsi untuk mengolah data Guru. Tampilan Form Guru dapat dilihat pada Gambar 4.5 berikut ini :

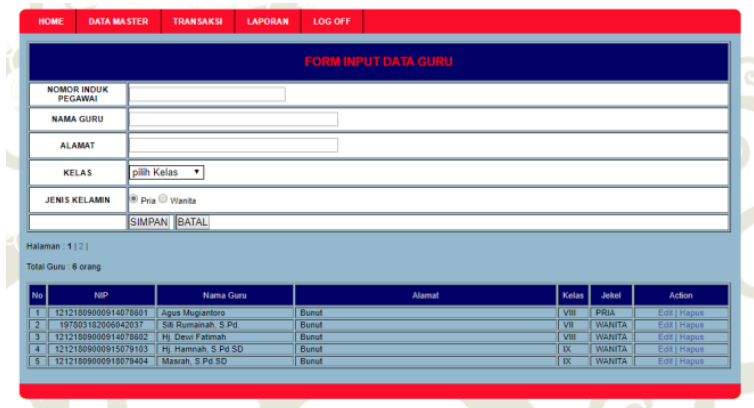

Gambar 4.5 Tampilan Form Guru

Link ini berfungsi untuk menampilkan form Absensi Siswa. seperti terlihat pada Gambar 4.6 berikut ini :

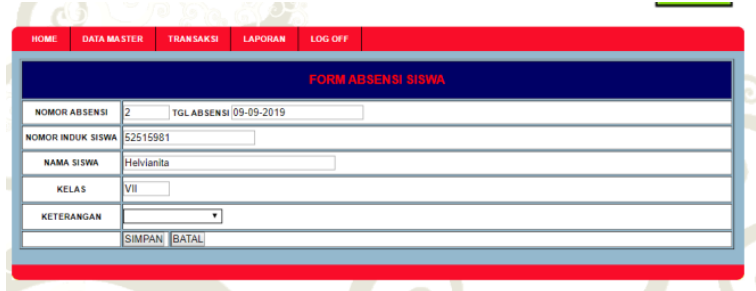

Gambar 4.6 Tampilan Transaksi Absensi Siswa

Form ini berfungsi untuk mengolah data Catatan Siswa. Tampilan Form Catatan Siswa dapat dilihat pada Gambar 4.7 berikut ini :

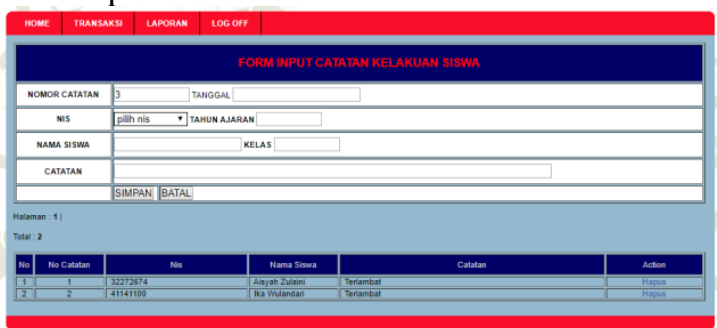

Gambar 4.7 Tampilan Form Catatan Siswa

Dari hasil penelitian yang dihasilkan berupa aplikasi ini dengan fitur-fitur ini memudahkan user dan sudah dilakukan tahapan pengujian dengan menggunakan metode Blackbox dengan hasil sebagai berikut :

\section{Pengujian (Testing)}

Pada tahap ini pengujian yang dilakukan yaitu Blackbox, peneliti melakukan uji coba terhadap sistem yang telah dibangun dengan hasil dan dengan bukti.

\section{Keunggulan Sistem}

Adapun kelebihan sistem baru adalah sebagai berikut : 
a. Sistem pengolahan data Monitoring Siswa menjadi lebih mudah, sehingga cukup efisien dan efektif dalam pengerjaannya.

b. Sistem pengolahan data Monitoring Siswa memiliki database yang cukup baik, sehingga dapat menampung data cukup besar.

\section{Kelemahan Sistem}

Selain mempunyai kelebihan, sebuah sistem baru pun sudah pasti mempunyai kekurangan sistem baru antara lain:

a. Biaya yang dibutuhkan untuk sistem pengolahan data Monitoring Siswa pada.tidak adanya pengamanan bila terjadi pencurian data.

b. Apabila terjadi kesalahan dalam penginputan data transaksi Monitoring Siswa, maka data yang sudah disimpan tidak dapat dirubah lagi.

\section{SIMPULAN}

Dari hasil dan pembahasan pada bab sebelumnya maka dapat diambil simpulan sebagai berikut :

1. Berdasarkan hasil dan pembahasan yang dilakukan dengan membangun aplikasi ini dapat memudahkan orang tua untuk mengetahui keadaan anaknya disekolah meliputi kehadiran siswa dan kedisplinannya

2. Aplikasi ini mudah dilakukan karena dapat diakses menggunakan smartphone walau belum dalam aplikasi apk.

3. Aplikasi ini harus ada perbaikan dan update sesuia kebutuhan program tersebut

4. Untuk pengguna sebaiknya dikumpulkan dan diberi arahan dan informasi mengenai penggunaan aplikasi khususnya untuk orang tua.

\section{DAFTAR PUSTAKA}

[1] Yusuf Sutarman (2010) Sistem Informasi Manajemen. Graha Ilmu : Yogyakarta.

[2] Ahmad Salamun (2013) Sistem Informasi Manajemen. Graha Ilmu : Yogyakarta.

[3] Edhy Sutanta (2010) Sistem Informasi Manajemen. Graha Ilmu :
Yogyakarta.

[4] Alim Sumarno (2012) Sistem Informasi Manajemen. Graha Ilmu : Yogyakarta.

[5] Widodo (2014) Teori dan Implememtasi. Edisi Revisi. Yogyakarta : Penerbit Andi.

[6] Syafitri, Y. (2016). PEMODELAN PERANGKAT LUNAK BERBASIS UML UNTUK PENGEMBANGAN SISTEM PEMASARAN AKBAR ENTERTAINMENT NATAR LAMPUNG SELATAN. Jurnal Cendikia, 14(1 April), 31-39. Retrieved from https://jurnal.dcc.ac.id/index.php/JC/a rticle/view/88 